\title{
Repat33 Acts as a Downstream Component of Eicosanoid Signaling Pathway Mediating Immune Responses of Spodoptera exigua, a Lepidopteran Insect
}

\author{
Md Tafim Hossain Hrithik, Mohammad Vatanparast (D), Shabbir Ahmed and Yonggyun Kim* \\ Department of Plant Medicals, College of Life Sciences, Andong National University, Andong 36729, Korea; \\ hrithik11605@gmail.com (M.T.H.H.); mvatanparast@korea.kr (M.V.); shabbirahmed.du@gmail.com (S.A.) \\ * Correspondence: hosanna@anu.ac.kr
}

check for

updates

Citation: Hrithik, M.T.H.;

Vatanparast, M.; Ahmed, S.; Kim, Y.

Repat33 Acts as a Downstream

Component of Eicosanoid Signaling

Pathway Mediating Immune

Responses of Spodoptera exigua, a

Lepidopteran Insect. Insects 2021, 12,

449. https://doi.org/10.3390/

insects12050449

Academic Editor: Julián F. Hillyer

Received: 22 April 2021

Accepted: 13 May 2021

Published: 14 May 2021

Publisher's Note: MDPI stays neutral with regard to jurisdictional claims in published maps and institutional affiliations.

Copyright: (C) 2021 by the authors Licensee MDPI, Basel, Switzerland. This article is an open access article distributed under the terms and conditions of the Creative Commons Attribution (CC BY) license (https:// creativecommons.org/licenses/by/ $4.0 /)$.
Simple Summary: Eicosanoids are oxygenated polyunsaturated fatty acids containing 20 carbons and subdivided into prostaglandin, leukotriene, and epoxyeicosatrienoic acid. They mediate immune responses in insects as well as mammals. Excessive eicosanoids cause severe inflammatory diseases in humans. However, a lack of eicosanoids induces immunosuppressive conditions in insects, which are highly susceptible to various entomopathogens. Despite the physiological significance of eicosanoids, their molecular action was not clearly understood in insects. This study was focused on Repat (Response to Pathogen) gene family, which might be regulated by eicosanoids. Among 44 members of Repat family genes, Repat33 was highly inducible to Gram-negative bacteria. Its expression was dependent on eicosanoids. Loss of function of Repat33 by RNA interference (RNAi) caused significant immunosuppression of a lepidopteran insect, Spodoptera exigua. Larvae of S. exigua treated by RNAi did not exhibit efficient cellular immune responses. They also failed to express antimicrobial peptide genes at high inducible levels in response to bacterial challenges. These results suggest that Repat33 is a downstream component of eicosanoid immune mediation.

Abstract: Repat (=response to pathogen) is proposed for an immune-associated gene family from Spodoptera exigua, a lepidopteran insect. In this gene family, 46 members (Repat1-Repat46) have been identified. They show marked variations in their inducible expression patterns in response to infections by different microbial pathogens. However, their physiological functions in specific immune responses and their interactions with other immune signaling pathways remain unclear. Repat33 is a gene highly inducible by bacterial infections. The objective of this study was to analyze the physiological functions of Repat33 in mediating cellular and humoral immune responses. Results showed that Repat33 was expressed in all developmental stages and induced in immune-associated tissues such as hemocytes and the fat body. RNA interference (RNAi) of Repat33 expression inhibited the hemocyte-spreading behavior which impaired nodule formation of hemocytes against bacterial infections. Such RNAi treatment also down-regulated expression levels of some antimicrobial genes. Interestingly, Repat33 expression was controlled by eicosanoids. Inhibition of eicosanoid biosynthesis by RNAi against a phospholipase $\mathrm{A}_{2}\left(\mathrm{PLA}_{2}\right)$ gene suppressed Repat33 expression while an addition of arachidonic acid (a catalytic product of $\mathrm{PLA}_{2}$ ) to RNAi treatment recovered such suppression of Repat33 expression. These results suggest that Repat33 is a downstream component of eicosanoids in mediating immune responses of S. exigua.

Keywords: immunity; repat; eicosanoid; $\mathrm{PLA}_{2}$; nodulation; AMP; Spodoptera exigua

\section{Introduction}

Insects can defend against microbial pathogens through their immune responses [1] Insect innate immunity involves programmed immune responses that are activated upon a pathogen attack [2]. To be specific, pathogen recognition receptors can recognize specific pathogen-associated molecular patterns upon immune challenge [3]. The recognition signal 
is then relayed to nearly all immune tissues such as hemocytes and fat body via various immune mediators [4]. These immune effectors can express cellular immune responses such as phagocytosis, nodule formation, encapsulation [5], and humoral immune responses such as melanization and antimicrobial peptide (AMP) gene expression [6].

Repat (response to pathogen) is an immune-associated gene family encoded in Spodoptera exigua, a lepidopteran insect [7]. Although Repat genes were initially discovered in the larval midgut after infection by Bacillus thuringiensis (Bt), their expression levels were also up-regulated by baculovirus infection [8]. Interestingly, some Repat genes are highly expressed in a Bt-resistant strain [8]. Repat proteins are relatively small $(\approx 15 \mathrm{kDa})$. They can interact with other Repat proteins [9]. For example, Repat1 is localized in the cytosol but translocated into the nucleus in the presence of Repat8 [10]. However, the functional associations of Repat proteins with immune responses are little understood.

Eicosanoids are a group of oxygenated C20 polyunsaturated fatty acids [11]. Eicosanoid biosynthesis is triggered by the hydrolysis of fatty acids for phospholipids using phospholipase $\mathrm{A}_{2}\left(\mathrm{PLA}_{2}\right)$ [12]. In S. exigua, three different $\mathrm{PLA}_{2}$ s have been identified. They play crucial roles in mediating immune functions [13-15]. Especially, secretory $\mathrm{PLA}_{2}\left(\mathrm{sPLA}_{2}\right)$ exhibits diverse roles in the digestion of dietary lipid in the midgut and in the production of eicosanoids to mediate immune responses $[15,16]$. Eicosanoid biosynthesis in insects is similar to that of mammalian systems but exhibits some deviation. Phospholipids in terrestrial insects have a little amount of arachidonic acid (AA) [17]. Thus PLA 2 catalyzes phospholipids to release linoleic acid which is then elongated and desaturated to form AA in S. exigua [18]. AA is then oxygenated by cyclooxygenase-like peroxynectin to produce $\mathrm{PGH}_{2}$, a prostaglandin (PG) precursor [13]. Finally, different PG synthases such as $\mathrm{PGE}_{2}$, $\mathrm{PGD}_{2}$, and $\mathrm{PGI}_{2}$ in S. exigua [19-21] can isomerize $\mathrm{PGH}_{2}$. Thromoboxane $\mathrm{B}_{2}$ is another type of prostanoid identified in S. exigua [22]. AA can also be oxygenated by different epoxygenases into four epoxyeicosatetraenoic acids in S. exigua [23]. Although leukotrienes are not identified in insects, they are known to play crucial roles in mediating immune responses in S. exigua [24]. All these eicosanoids can mediate immune responses and reproductive processes in S. exigua [4].

With the discovery of the $\mathrm{PGE}_{2}$ receptor from Manduca sexta, another lepidopteran insect, the eicosanoid immune signaling pathway has been investigated [25]. A similar PGE $_{2}$ receptor of $S$. exigua can also use cAMP secondary messenger to activate actin cytoskeleton rearrangement during hemocyte-spreading behavior in cellular immune responses [26]. These findings suggest that other downstream components of the $\mathrm{PGE}_{2}$ immune signaling pathway are activated to mediate cellular and humoral immune responses.

Inducible expression of Repat family genes in response to immune challenge led us to impose a hypothesis that they might be downstream components of the eicosanoid immune signaling pathway. To test this hypothesis, we selected a specific Repat gene, Repat33, which was highly inducible by bacterial infection, and assessed its immune-associated function using RNA interference (RNAi) by monitoring any loss of functions. Then we investigated the functional link between eicosanoid signaling and Repat33 expression via PLA 2 .

\section{Materials and Methods}

\subsection{Insect Rearing}

S. exigua larvae were collected from a Welsh onion field in Andong, Korea, and reared with an artificial diet [27] at $25 \pm 1^{\circ} \mathrm{C}$. They underwent five instars (L1-L5). Sugar solution $(10 \%)$ was used as an adult diet.

\subsection{Immune Challenge}

Escherichia coli Top10 Gram-negative bacterium was obtained from Invitrogen (Carlsbad, CA, USA) and cultured on Luria-Bertani (LB) medium. For the immune challenge, bacteria were killed by heat treatment at $95^{\circ} \mathrm{C}$ for $10 \mathrm{~min}$. Not a single colony of heattreated bacteria grew on LB medium. Enterococcus mundtii, a Gram-positive bacterium, was isolated from a nematode [28]. It was cultured with tryptic soy broth and heat-killed for the 
immune challenge. Autographa californica multiple nucleopolyhedrosis virus (AcMNPV), a baculovirus, was cultured using Sf9 cells according to the method described by Jung and Kim [29]. Metarhizium rileyi, an entomopathogenic fungus, was isolated from infected S. exigua in a welsh onion field [30] and cultured on solid potato dextrose agar medium ( $5 \%$ potato extract, $0.5 \%$ dextrose, $1.7 \%$ agar) at $25{ }^{\circ} \mathrm{C}$ for 7 days. Conidia suspension was prepared by scraping the fungal culture into $0.1 \%$ Triton $X-100$ solution and counted using a Neubauer hemocytometer (Marienfeld-Superior, Lauda-Königshofen, Germany) under $40 \times$ magnification. For the immune challenge, L5 larvae were injected in $1 \mu \mathrm{L}$ of bacteria ( $10^{4}$ cells /larva), 1000 conidia of $M$. rileyi, or AcMNPV in a budded form $\left(10^{4}\right.$ plaque-forming unit (pfu)/larva).

\subsection{Chemicals}

Arachidonic acid (AA: 5,8,11,14-eicosatetraenoic acid) and dexamethasone (DEX:(11ß, 16 $\alpha$ )-9-fluoro-11,17,21-trihydroxy-16-methylpregna-1,4-diene-3,20-dione) were purchased from Sigma-Aldrich Korea (Seoul, Korea). Both were dissolved in dimethyl sulfoxide (DMSO). Diethyl pyrocarbonate (DEPC) water was prepared by mixing $1 \mathrm{~mL}$ of DEPC with $1 \mathrm{~L}$ of deionized distilled water followed by $12 \mathrm{~h}$ incubation at $37^{\circ} \mathrm{C}$. DEPC-Treated water was then autoclaved. Anticoagulant buffer was prepared with $186 \mathrm{mM} \mathrm{NaCl}, 17 \mathrm{mM}$ $\mathrm{Na}_{2}$ EDTA, and $41 \mathrm{mM}$ citric acid. Its $\mathrm{pH}$ was then adjusted to 4.5 with $\mathrm{HCl}$. Phosphatebuffered saline (100 $\mathrm{mM}$ phosphate containing $0.7 \% \mathrm{NaCl}$, $\mathrm{pH} 7.4$ ) was prepared.

\subsection{Larval Tissue Preparation}

Three-day-old L5 larvae were used to collect different tissues including hemocytes, fat body, midgut, and epidermis. Hemolymph was collected by cutting prolegs and centrifuged at $800 \times g$ for 5 min to obtain a hemocyte pellet. After hemolymph collection, larvae were used to isolate other tissues such as fat body, midgut, and epidermis. Each tissue sample was prepared from five L5 larvae and replicated three times.

\subsection{RNA Extraction and cDNA Preparation}

From different developmental stages and different tissues, total RNAs were extracted using Trizol reagent (Invitrogen). RNA was resuspended in DEPC water and heated at $50{ }^{\circ} \mathrm{C}$ for $15 \mathrm{~min}$. RNA concentration was measured with a spectrophotometer (Nanodrop, Thermo Fisher Scientific, Wilmington, DE, USA). For cDNA preparation, $2 \mu \mathrm{g}$ of RNA was mixed with oligo-dT and reverse transcriptase (Intron Biotechnology, Seoul, Korea).

\subsection{Bioinformatics Analysis}

S. exigua Repat gene sequences were obtained from the transcriptomic databases (PRJNA634227). Prediction of protein domain structure was performed using Pfam (http:/ / pfam.xfam.org, accessed on 14 May 2020) and Prosite (https:/ / prosite.expasy.org/, accessed on 14 May 2020).

\subsection{RT-PCR and RT-qPCR}

RT-PCR was performed using DNA Taq polymerase (GeneAll, Seoul, Korea) with gene-specific primers (Table S1) and a sequential temperature cycle of $95{ }^{\circ} \mathrm{C}$ for $30 \mathrm{~s}$, $52{ }^{\circ} \mathrm{C}$ for $30 \mathrm{~s}$, and $72{ }^{\circ} \mathrm{C}$ for $30 \mathrm{~s}$. After 35 cycles, the PCR product was assessed by $1 \%$ agarose gel electrophoresis. RT-qPCR was performed using a CFXC connect real-time PCR Detection System (BioRad, Hercules, CA, USA) with a SYBER Green Real-Time PCR Master Mix (Toyobo, Osaka, Japan) according to the guideline provided by Bustin et al. [31]. A ribosomal protein, $R L 32$, was used as a stably expressed reference gene [13].

\subsection{RNA Interference (RNAi)}

T7 promoter sequence was attached to gene-specific primers at the $5^{\prime}$ end. Using these primers, a partial gene (297 bp) of Repat33 was amplified with the method described above. Using this PCR product, double-stranded RNA (dsRNA) was prepared with a Megascript 
RNAi Kit (Ambion, Austin, TX, USA). dsRNA was combined with a transfection reagent (Metafectene Pro, Biontex, Planegg, Germany) at a 1:1 ratio. A microsyringe (Hamilton, Reno, NV, USA) equipped with a 26-gauge needle was used to inject the dsRNA sample to L5 larvae at a dose of $1 \mu \mathrm{g}$ dsRNA per larva. RNA efficiency was estimated by RT-qPCR at $48 \mathrm{~h}$ post-injection (PI). Each treatment was replicated three times with independent RNA preparation. For RNAi of $S e-s P L A_{2}$, we followed the method described previously [15].

\subsection{Hemocyte-Spreading Behavior Analysis}

L5 larvae were treated with RNAi. After $24 \mathrm{~h}$, they were injected with E. coli ( $10^{4}$ cells/larva). After $8 \mathrm{~h}$ of incubation at $25^{\circ} \mathrm{C}$, approximately $100 \mu \mathrm{L}$ of hemolymph was obtained and mixed with $800 \mu \mathrm{L}$ of the anticoagulant buffer. After $5 \mathrm{~min}$ of incubation on ice, the cell suspension was centrifuged at $800 \times \mathrm{g}$ for $5 \mathrm{~min}$. Then $700 \mu \mathrm{L}$ of the supernatant was replaced with $250 \mu \mathrm{L}$ of TC100 insect culture medium (Welgene, Gyeongsan, Korea) to prepare a hemocyte suspension. For quantification of hemocyte-spreading behavior, $50 \mu \mathrm{L}$ of the hemocyte suspension was added to each well of a 96-well microplate and incubated at $25^{\circ} \mathrm{C}$ for $40 \mathrm{~min}$ under darkness. Spread hemocytes were determined from randomly chosen 100 hemocytes by cytoplasmic extension beyond cell boundary. For F-actin analysis, $10 \mu \mathrm{L}$ of the hemocyte suspension was used to observe cells after incubation in a wet chamber under darkness. After removing the supernatant, attached cells were fixed with $3.7 \%$ paraformaldehyde at room temperature (RT) for $10 \mathrm{~min}$. After washing three times, cells were permeabilized with PBS containing Triton X-100 for $2 \mathrm{~min}$. These permeabilized cells were then incubated with 5\% skimmed milk to block the background for $10 \mathrm{~min}$ at RT. Cells were then incubated with fluorescein isothiocyanate (FITC)-tagged phalloidin (Alexa Fluor 488 phalloidin, $1 \mu \mathrm{g} / \mathrm{mL}$, Thermo Scientific, Rockford, IL, USA) in PBS at RT for $1 \mathrm{~h}$. Before mounting slides, cells were stained with $4^{\prime}$,6-diamidino-2-phenylindole (DAPI, $1 \mu \mathrm{g} / \mathrm{mL}$, Thermo Scientific) in PBS. Hemocyte-spreading was observed under a fluorescence microscope (DM2500, Leika, Wetzlab, Germany). Hemocyte-spreading was determined by the extension of F-actin out of the original cell boundary. Hemocyte-spreading behavior was quantified by randomly assessing 100 cells. Each treatment was replicated three times.

\subsection{Nodulation Assay}

Two-day-old L5 larvae were used for hemocyte nodule formation bioassays. Heatkilled E. coli was injected at a dose of $1.63 \times 10^{4}$ cells per larva through proleg and incubated at RT for $8 \mathrm{~h}$. For RNAi, bacteria were injected at $48 \mathrm{~h}$ PI of dsRNA. After dissection of test larvae, melanized nodules were counted under a stereoscopic microscope (Stemi SV11, Zeiss, Jena, Germany) at $50 \times$ magnification. Each treatment was replicated three times.

\subsection{Expression Analysis of Antimicrobial Peptide (AMP) Genes}

Expression levels of AMP genes were analyzed using L5 larvae after immune challenge with heat-killed E. coli as described above. At $8 \mathrm{~h}$ after immune challenge, different tissues were prepared and used to extract total RNAs. RT-qPCR was performed as described above against 10 AMP genes with gene-specific primers (Table S1). Each treatment was replicated three times.

\subsection{Data Analysis}

All data were analyzed using PROC GLM of the SAS program [32]. Means were compared by LSD test at Type I error $=0.05$.

\section{Results}

\subsection{Repat Family Is Subdivided into Three Groups}

Repat family was initially reported in the transcriptome of S. exigua (GenBank accession number: PRJNA634227), in which 46 members were deposited in NCBI GenBank. These Repat genes were phylogenetically classified into three groups (Figure 1a). Group I was the largest subfamily. It contained 24 members. This group was further subdivided 
into four clusters: Ia, Ib, Ic, and Id. Group II contained 17 members. Group III contained only five Repat genes. Repat33 was classified into Group Ia along with Repat31 and Repat32.

Repat genes showed various inducible expression patterns after challenges with different pathogens (Figure 1b). Some Repat genes in Groups II and III were inducible after a viral infection. In contrast, some Repat genes in Group I was inducible after a bacterial infection as well as after a viral infection. However, Repat33 was only highly inducible after infection of Gram-negative bacteria and used for subsequent functional assay in response to the bacterial immune challenge.

\subsection{Expression Profile of Repat33}

Based on the predicted amino acid sequence of Repat33, its product is a small (110 amino acid residues) secretory protein with a signal peptide in its amino-terminal region. It also possessed a transcription factor domain (Figure 2a). It was expressed in all developmental stages, from the egg stage to the adult stage (Figure 2b). Especially, it was highly expressed in the L5 larval stage. Four different tissues (midgut, epidermis, fat body, and hemocytes) expressed Repat33 at the L5 stage. In response to bacterial immune challenge, all tested tissues showed significantly $(p<0.05)$ increased expression of Repat33.

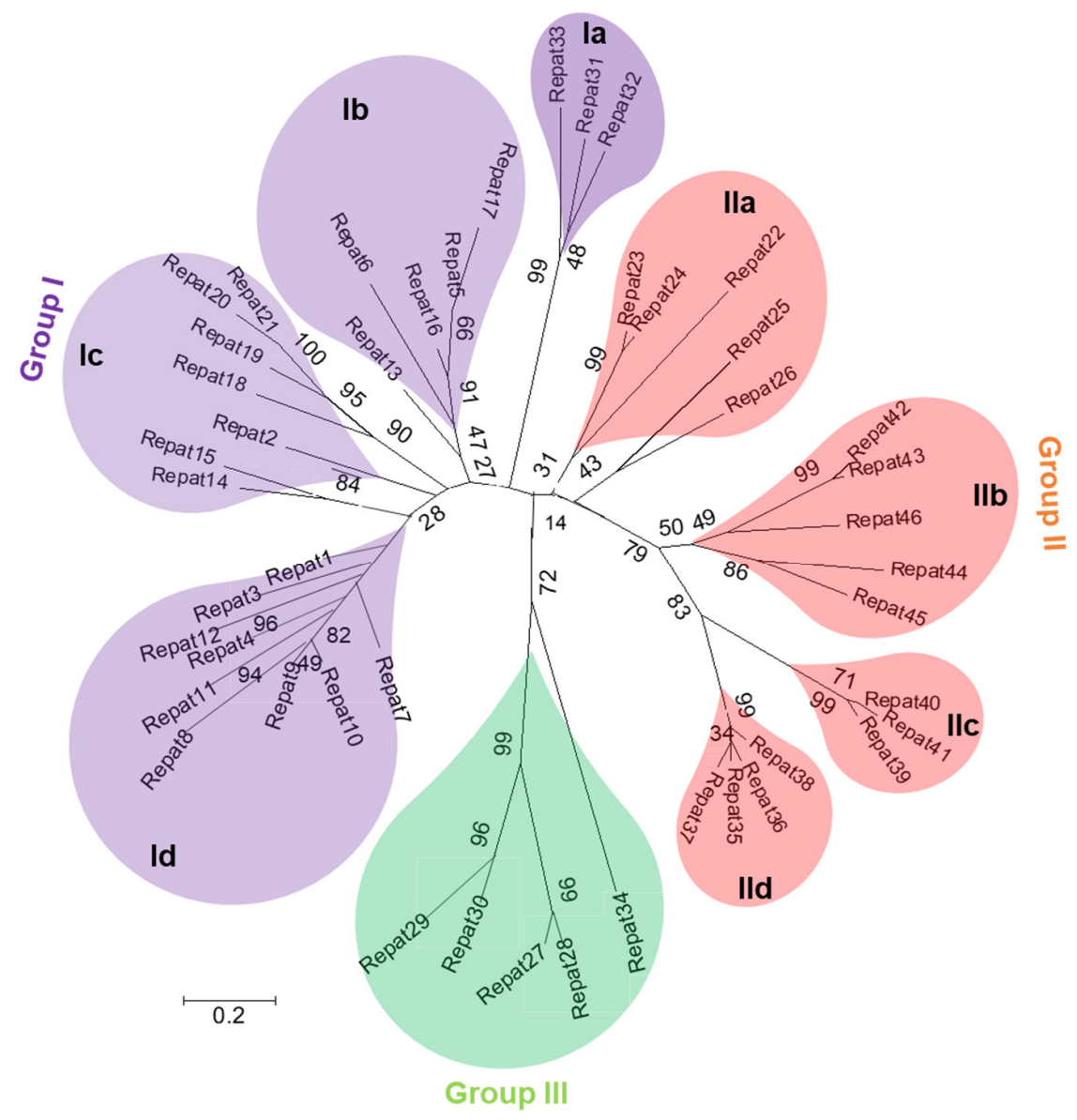

(a)

Figure 1. Cont. 

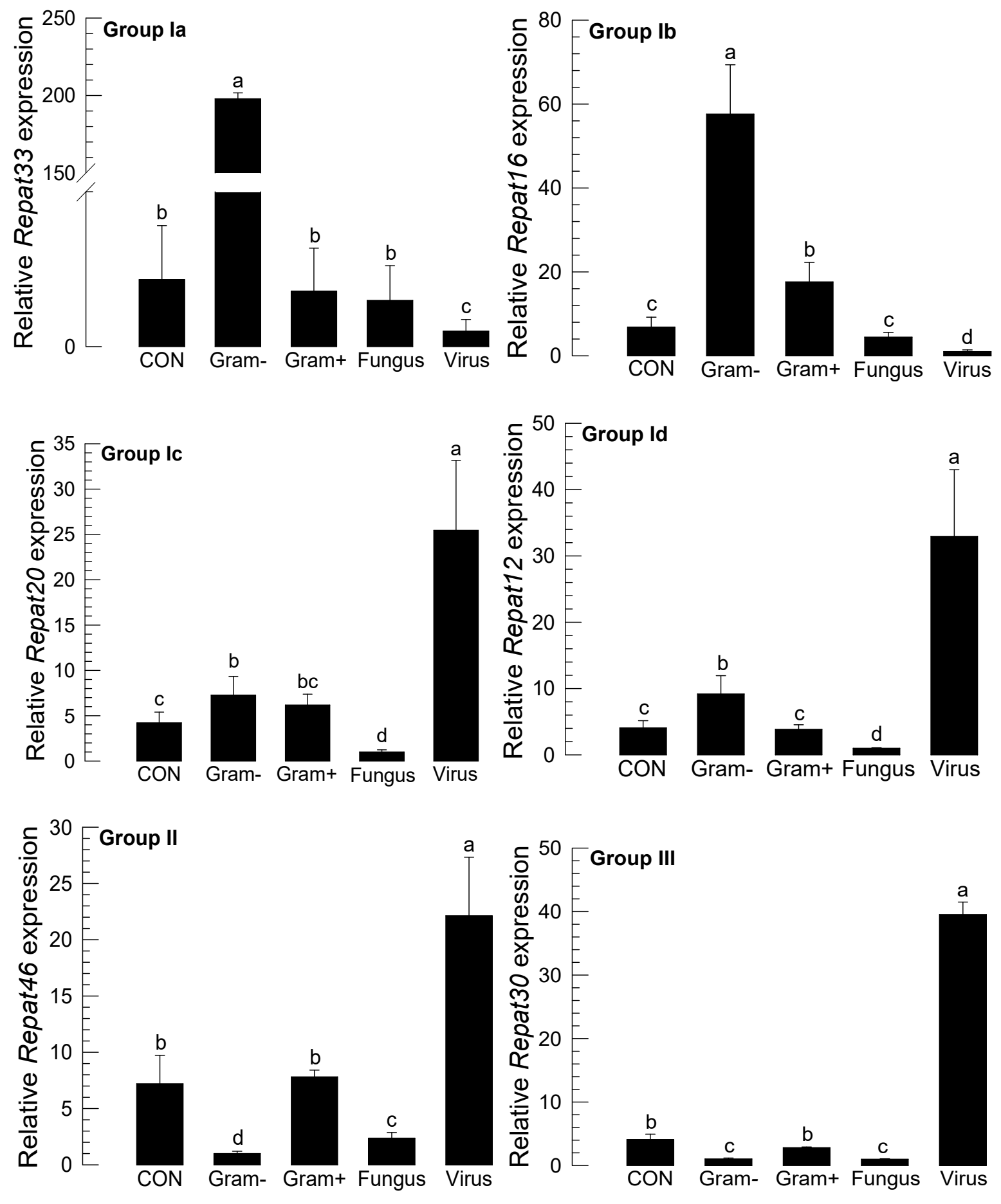

(b)

Figure 1. Classification of Repat family genes of S. exigua. (a) Phylogenetic analysis of 46 Repat genes. The analysis was performed using MEGA6. Bootstrapping values were obtained with 1000 repetitions to support branching and clustering. Amino acid sequences of selected genes were retrieved from GenBank with an accession number of PRJNA634227. (b) Expression of Repat genes induced by different pathogens. 'Gram-' and 'Gram+' represent E. coli and E. mundtii bacteria, respectively. Fungus and virus represent $M$. rileyi and AcMNPV, respectively. Immune challenge used a hemocoelic injection of bacteria ( $10^{4}$ cells / larva), fungus (1000 conidia/larva), or virus ( $10^{4} \mathrm{pfu} /$ larva). After $8 \mathrm{~h}$ of incubation, total RNAs were extracted from the fat body and used for constructing cDNAs. A ribosomal gene, RL32, was used as a reference gene for RT-qPCR. Each treatment was replicated three times with independent tissue preparations. Different letters indicate significant differences among means at Type I error $=0.05$ (LSD test). 


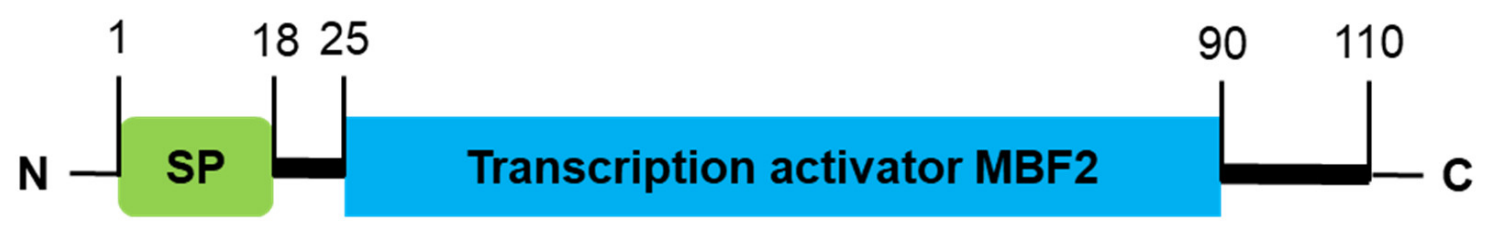

(a)
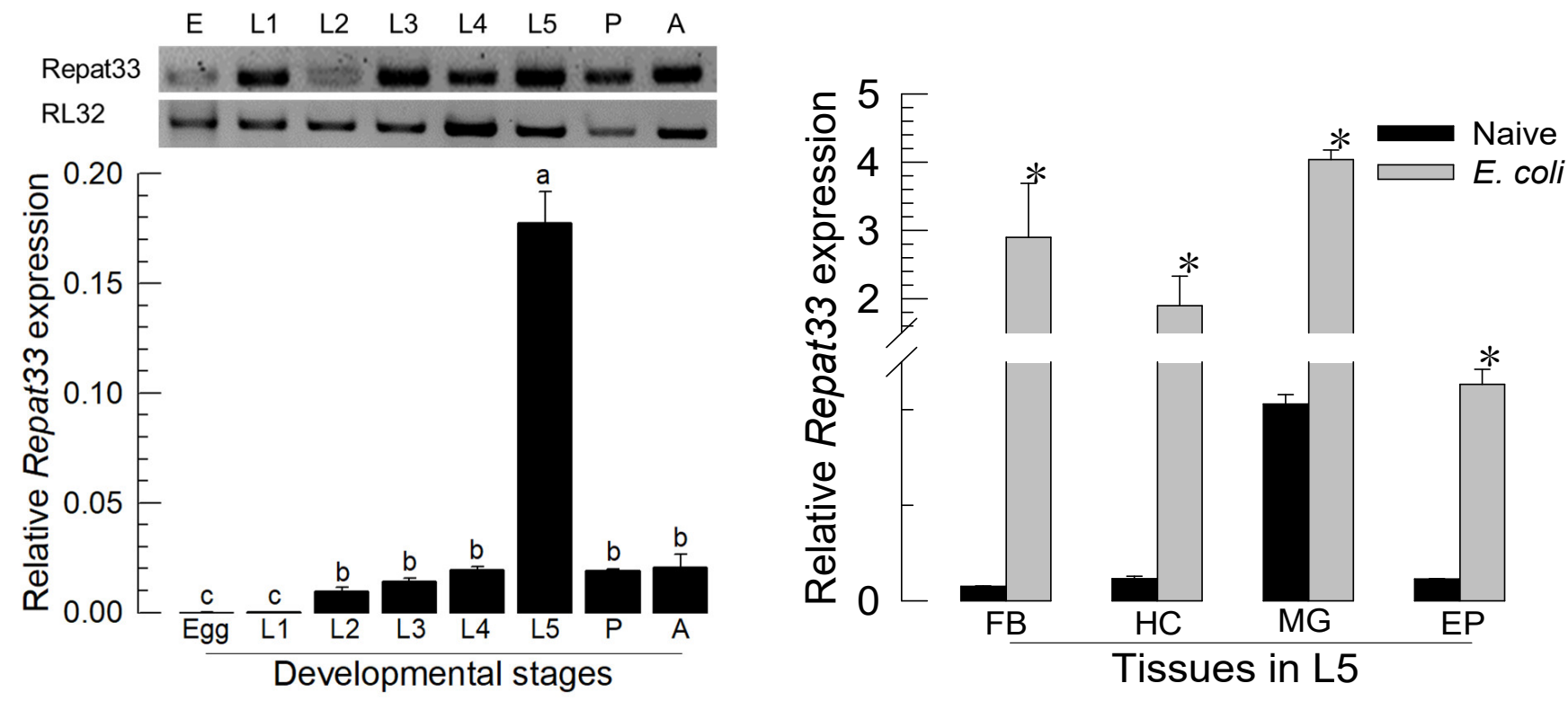

(b)

Figure 2. Expression profile of Repat33 in S. exigua. (a) Domain analysis. 'SP' stands for signal peptide. (b) Expression levels of Repat33 in different developmental stages including egg, first to fifth instar larvae ('L1-L5'), pupa ('P'), and adult ('A'), and different tissues of $\mathrm{L} 5$ including the fat body ('FB'), hemocyte ('HC'), midgut ('MG'), and epidermis ('EP'). For the immune challenge, E. coli ( $10^{4}$ cells/larva) was injected into L5 larvae followed by incubation for $8 \mathrm{~h}$ at $25^{\circ} \mathrm{C}$. A ribosomal gene, $R L 32$, was used as a reference gene. Each treatment was replicated three times with independent biological sample preparations. Different letters in developmental analysis indicate significant differences among means at Type I error $=0.05$ (LSD test). Asterisks in tissue analysis indicate a significant difference between naïve and immune challenge.

\subsection{RNAi of Repat33 and Subsequent Influence on Immune Responses}

RNAi was performed by injecting $1 \mu \mathrm{g}$ of dsRNA specific to Repat33 to larval hemocoel of S. exigua (Figure 3a). Expression levels of Repat 33 were significantly $(p<0.05)$ reduced by dsRNA injection. At $24 \mathrm{~h}$ after dsRNA injection, the expression level of Repat33 was reduced by more than $90 \%$. After that, its expression level began to increase, fully recovering to control level at $72 \mathrm{~h}$ after dsRNA injection.

Under this RNAi condition, hemocytes significantly lost their spreading behavior (Figure $3 \mathrm{~b}$ ). When the actin cytoskeleton was observed after staining F-actin using FITClabeled phalloidin, control hemocytes exhibited extensive cytoplasmic extension while hemocytes collected from RNAi-treated larvae did not. The number of nodules formed in response to the bacterial challenge was significantly $(p<0.05)$ decreased after treatment with Repat33 dsRNA compared to that after treatment with dsRNA control (Figure 3c). 


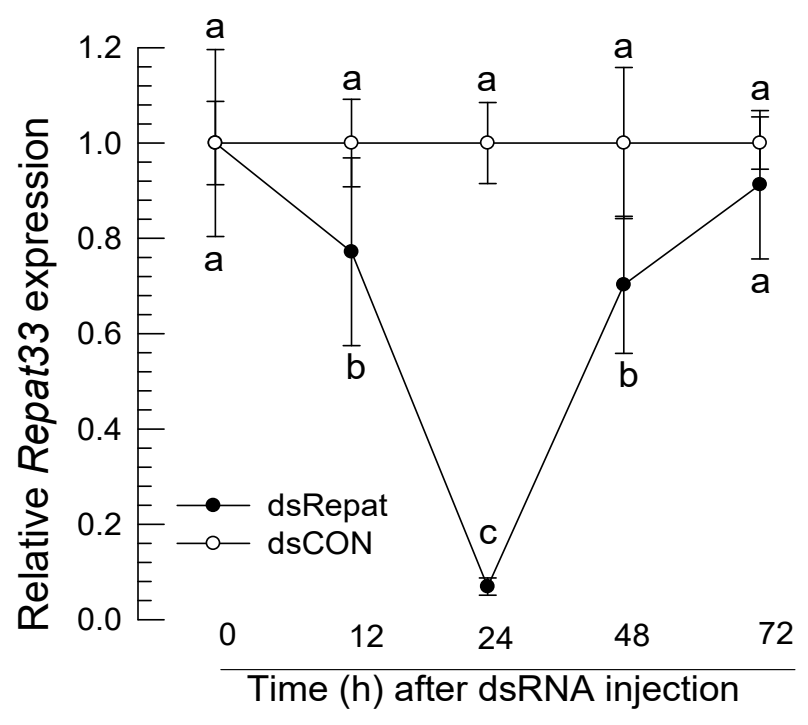

(a)
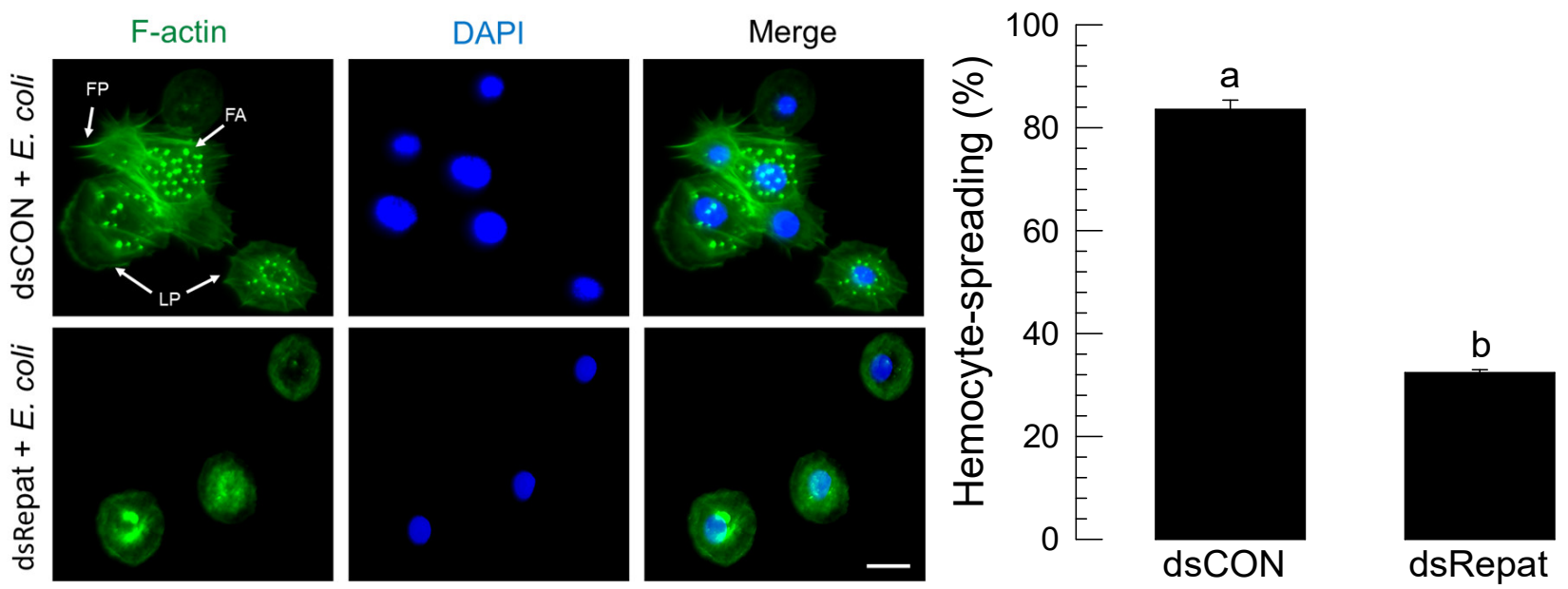

(b)
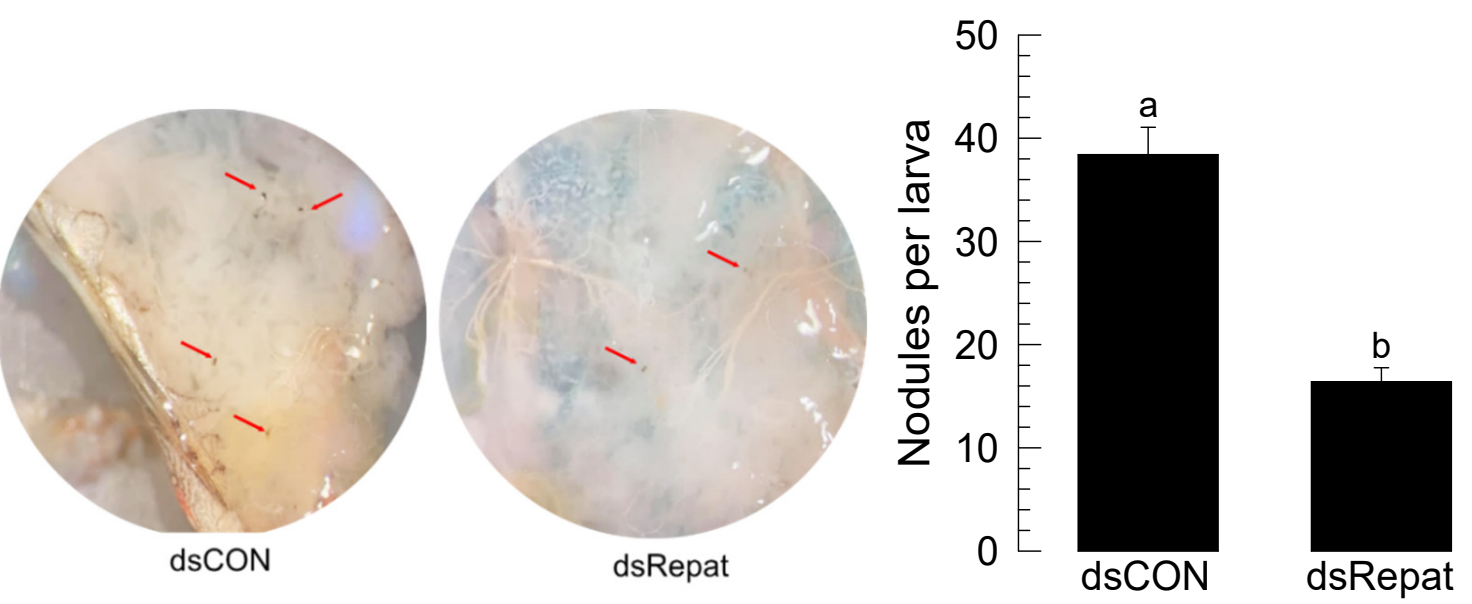

(c)

Figure 3. Effect of RNA interference (RNAi) of Repat33 expression on cellular immune responses of L5 larvae of $S$. exigua. (a) Change of Repat33 expression level in fat body after injection of dsRNA ('dsRepat', $1 \mu \mathrm{g} / \mathrm{larva}$ ) specific to Repat33. A 
GFP gene was used to construct control dsRNA ('dsCON'). Each treatment was replicated three times with independent tissue preparations. (b) Influence of RNAi on hemocyte-spreading behavior in response to bacterial challenge. E. coli $\left(10^{4}\right.$ cells / larva) was injected to L5 larvae at $24 \mathrm{~h}$ after injection of dsRepat. At $8 \mathrm{~h}$ after injection, hemolymph was collected and used for the hemocyte-spreading assay. For cytoskeleton analysis, hemocytes were observed under a fluorescence microscope at $400 \times$ magnification. Filopodia ('FP'), focal adhesion ('FA'), and lamellipodia ('LP') were indicated by white arrows. F-actin filaments were specifically recognized by FITC-tagged phalloidin (green). The nucleus was stained with DAPI (blue). Each treatment was independently replicated three times. Scale bar represents $10 \mu \mathrm{m}$. (c) Influence of RNAi on nodule formation in response to bacterial challenge $\left(1.63 \times 10^{4}\right.$ cells /larva). Nodules were counted at $8 \mathrm{~h}$ post-injection. Each treatment was independently replicated three times. Different letters indicate significant differences among means at Type I error $=0.05$ (LSD test).

Humoral immune response was assessed by measuring expression levels of 10 AMP genes in four tissues: fat body ('FB'), hemocytes ('HC'), midgut $\left(\mathrm{MG}^{\prime}\right)$, and epidermis ('EP') (Figure 4). In naïve larvae, the AMP expression profile varied among tissues. In the fat body, lysozyme was highly expressed while attacin-1 in hemocytes, defensin in the midgut, and gloverin in the epidermis were highly expressed. Expression levels of several AMP genes were reduced after RNAi treatment. However, the susceptibility to treatment with RNAi specific to Repat33 varied among four tissues. In the midgut, expression levels of most AMP genes except apolipophorin III were reduced after RNAi treatment. In the epidermis, expression levels of most genes except attacin-2 and gallerimycin were reduced after RNAi treatment. In hemocytes, expression levels of attacin-2, defensin, two transferrin genes, and cecropin were reduced after RNAi treatment. In the fat body, expression levels of two attacin genes, gallerimycin, lysozyme, and cecropin were reduced after RNAi treatment. In all tissues, cecropin expression was highly susceptible to treatment with RNAi specific to Repat33. These results indicate that Repat33 can regulate tissue-specific expression of AMP genes.

\subsection{Repat33 Expression Is Controlled by Eicosanoids}

Repat33 expression was inducible to bacterial challenge. However, treatment with dexamethasone known to inhibit $\mathrm{PLA}_{2}$ to block eicosanoid biosynthesis significantly $(p<0.05)$ suppressed the inducible expression of Repat33 in response to bacterial challenge (Figure 5a). The addition of arachidonic acid (a catalytic product of $\mathrm{PLA}_{2}$ ) significantly rescued such inhibition of inducible Repat33 expression caused by dexamethasone treatment.

To see the influence of $\mathrm{PLA}_{2}$ on Repat33 expression, RNAi specific to $\mathrm{PLA}_{2}$ was performed. The expression level of Repat33 was then monitored. Results are shown in Figure $5 \mathrm{~b}$. As expected, bacterial challenge induced the expression of Repat33. However, RNAi specific for PLA 2 expression significantly reduced Repat33 expression even after bacterial challenge. However, the addition of arachidonic acid significantly $(p<0.05)$ rescued the inhibition of Repat33 expression induced by treatment with RNAi specific for PLA 2 .

To clarify types of eicosanoids that mediated the induction of Repat33 expression, two different eicosanoid biosynthesis inhibitors, ibuprofen ('IBU', prostaglandin (PG) biosynthesis inhibitor) and esculetin ('ESC', leukotriene biosynthesis inhibitor), were assessed. As shown in Figure $5 c$, both inhibitors significantly $(p<0.05)$ suppressed the inducible expression of Repat33, with the PG biosynthesis inhibitor being more potent. Addition of $\mathrm{PGE}_{2}$ significantly $(p<0.05)$ rescued Repat33 expression.

\subsection{Repat33 Is a Downstream Component of PGE2 Signaling Pathway}

The influence of $\mathrm{PGE}_{2}$ mediation on Repat33 expression was analyzed in cellular and humoral immune responses (Figure 6). Hemocyte-spreading behavior induced by bacterial challenge was significantly inhibited by RNAi treatment against Repat33 expression (Figure 6a). $\mathrm{PGE}_{2}$ also stimulated the hemocyte behavior. However, it failed to induce such cellular immune response under RNAi treatment specific for Repat33. 

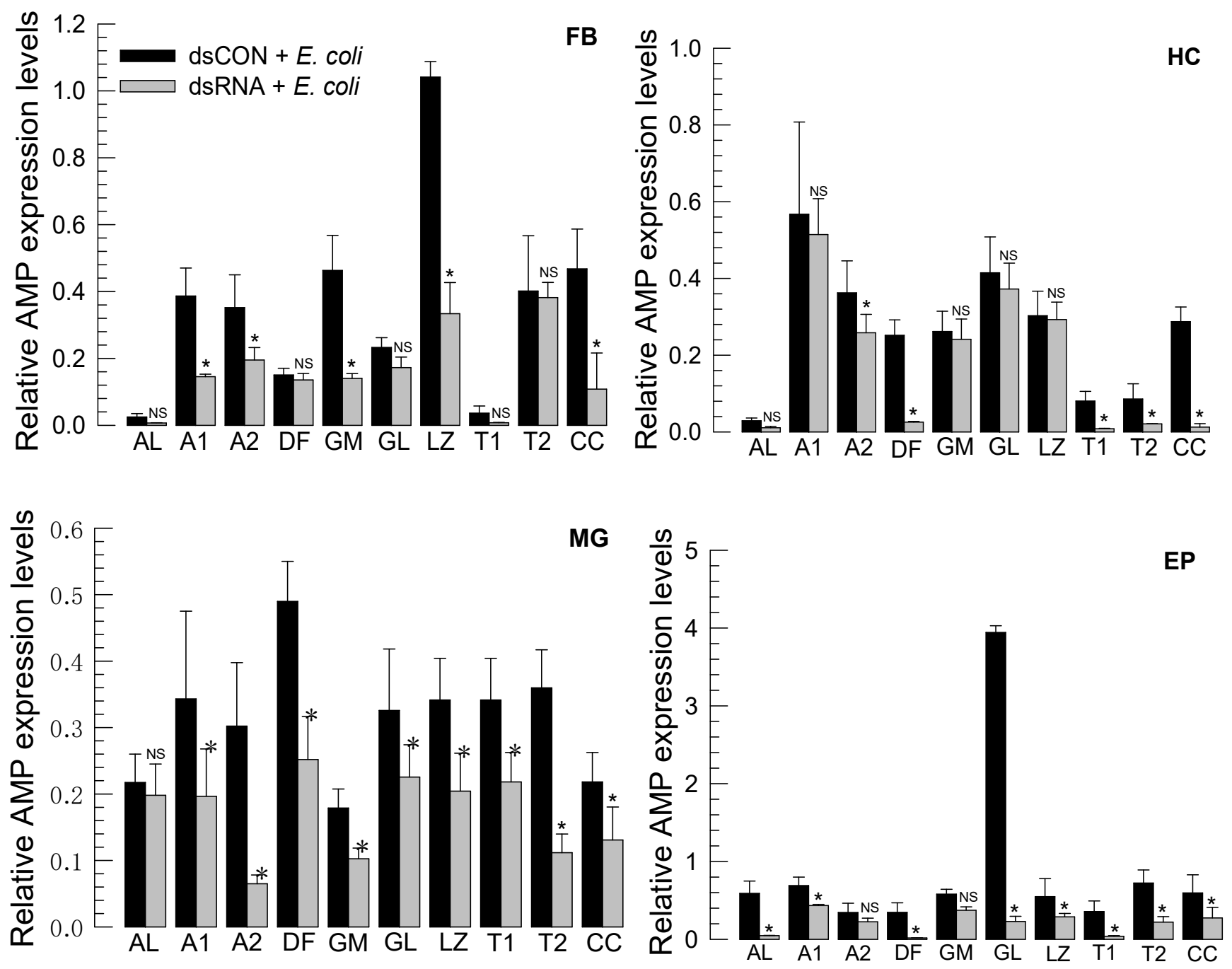

Figure 4. Effect of RNA interference (RNAi) of Repat33 expression on humoral immune responses of L5 larvae of S. exigua. Humoral immune responses were assessed by quantifying expression levels of 10 antimicrobial peptides (AMP) genes: apolipophorin III ('AL'), attacin 1 ('A1'), attacin 2 ('A2'), defensin ('DF'), gallerimycin ('GM'), gloverin ('GL'), lysozyme ('LZ'), transferrin $1\left({ }^{\prime T} 1^{\prime}\right)$, transferrin 2 ('T2'), and cecropin ('CC'). L5 larvae were injected with dsRNA ('dsRepat', $1 \mu \mathrm{g} /$ larva) specific for Repat33. At $24 \mathrm{~h}$ after injection, larvae were injected with $E$. coli ( $10^{4}$ cells/larva) and incubated at room temperature for $24 \mathrm{~h}$. Total RNAs were extracted from different tissues [fat body ('FB'), midgut ('MG'), hemocyte ('HC'), and epidermis $\left.\left({ }^{\prime} \mathrm{EP}^{\prime}\right)\right]$ and used for constructing cDNAs. A GFP gene was used to construct control dsRNA ('dsCON'). Each treatment was replicated three times with independent tissue preparations. A ribosomal protein gene, $R L 32$, was used as an internal control for RT-qPCR. Each treatment was replicated three times. Asterisks indicate significant differences exist $(p<0.05)$.

Inducible expression of cecropin in four different tissues was commonly inhibited by RNAi of Repat33 expression. This gene induction process was clarified by $\mathrm{PGE}_{2}$ mediation (Figure 6b). PGE 2 without bacterial challenge significantly induced cecropin expression. However, RNAi specific to Repat33 expression significantly suppressed the inducible gene expression of cecropin. Interestingly, such suppression was not rescued by the addition of $\mathrm{PGE}_{2}$. This indicates that $\mathrm{PGE}_{2}$ in response to the bacterial challenge can induce Repat33 which mediates both cellular and humoral immune responses (Figure 6c). 


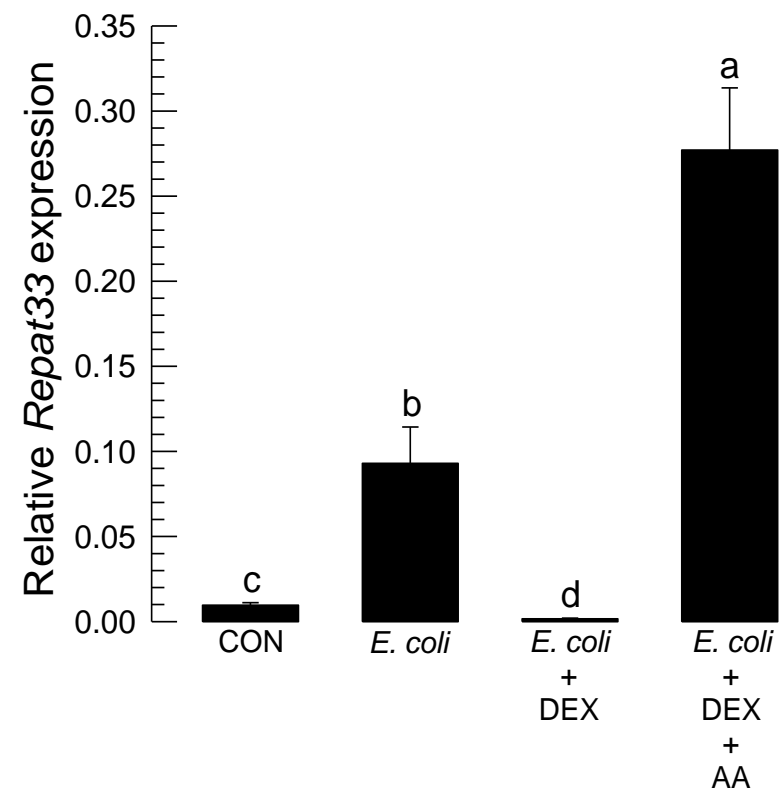

(a)

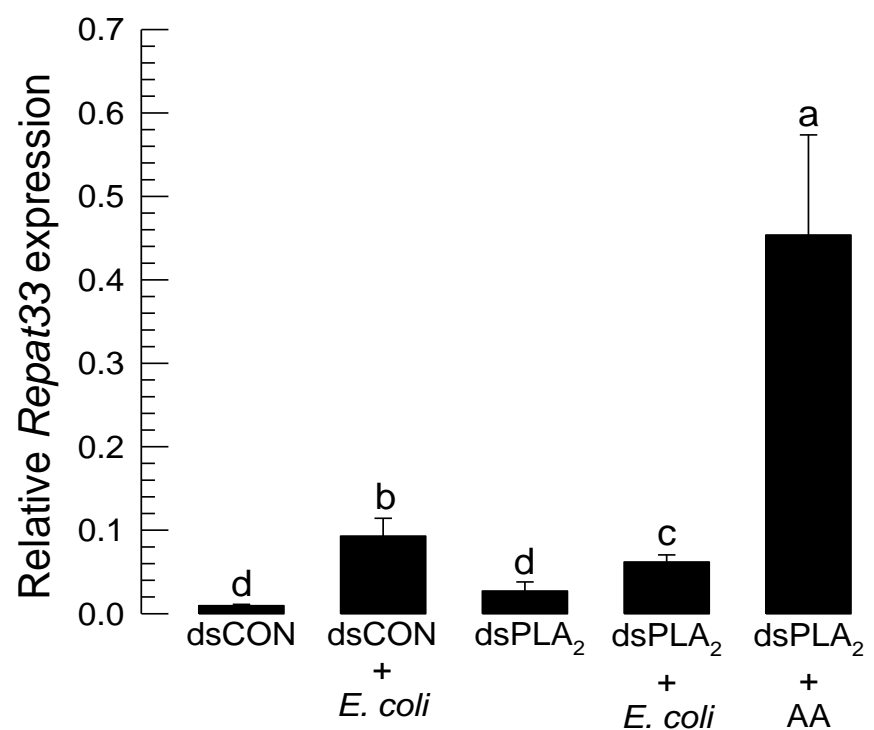

(b)

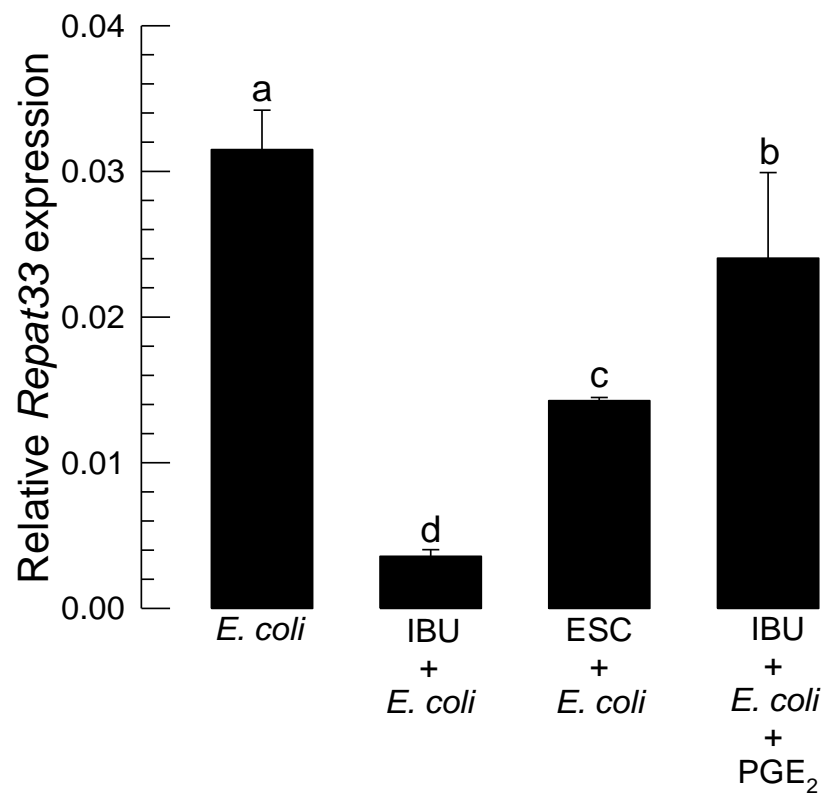

(c)

Figure 5. Influence of eicosanoids on Repat33 expression in L5 larvae of S. exigua. For the immune challenge, E. coli ( $10^{4}$ cells/larva) was injected into L5 larvae followed by incubation at $25^{\circ} \mathrm{C}$ for $8 \mathrm{~h}$. (a) Inhibitory effect of dexamethasone ('DEX', a specific PLA 2 inhibitor, $1 \mu \mathrm{g} /$ larva) on Repat33 expression. The addition of arachidonic acid (AA, a catalytic product of PLA $\mathrm{P}_{2}, 1 \mu \mathrm{g} /$ larva) rescued Repat33 expression suppressed by DEX. (b) Inhibitory effect of RNA interference (RNAi) of a PLA 2 gene (= Se-sPLA 2 ) of $S$. exigua on Repat33 expression. RNAi was performed by injecting $1 \mu \mathrm{g}$ of dsRNA ('dsPLA2') specific to Se-sPLA 2 to each larva. A GFP gene was used to construct a control dsRNA ('dsCON'). At $24 \mathrm{~h}$ after dsRNA injection, larvae were subjected to immune challenge. At $8 \mathrm{~h}$ after injection, total RNA was isolated from the fat body for RT-qPCR analysis of Repat33 expression. (c) Effect of ibuprofen ('IBU', a COX inhibitor, $1 \mu \mathrm{g} / \mathrm{larva}$ ) or esculetin ('ESC', a LOX inhibitor, $1 \mu \mathrm{g} /$ larva) on Repat33 expression. The addition of PGE 2 (a catalytic product of COX, $1 \mu \mathrm{g} / \mathrm{larva}$ ) rescued Repat33 expression suppressed by IBU or ESC. A ribosomal protein gene, RL32, was used as a reference gene for RT-qPCR. Each treatment was replicated three times with independent biological sample preparations. Different letters indicate significant differences among means at Type I error $=0.05$ (LSD test). 


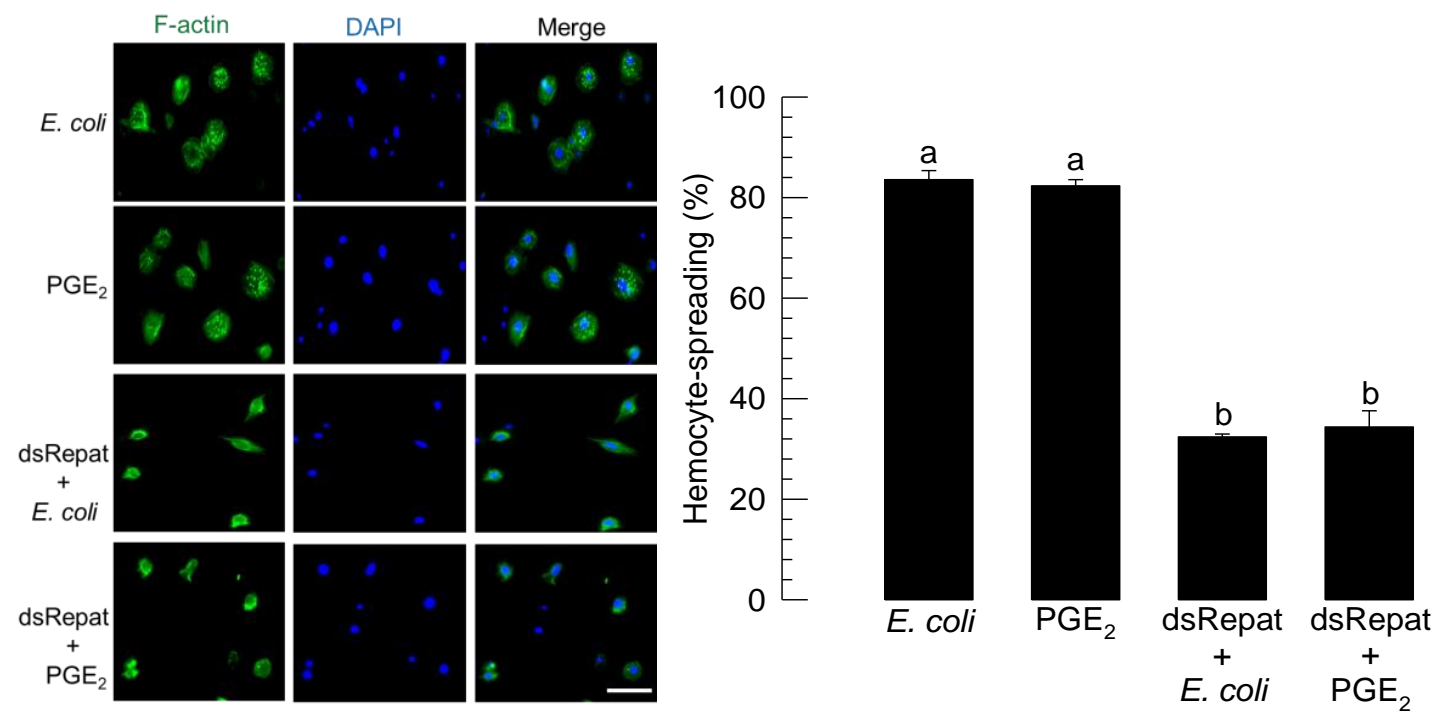

(a)
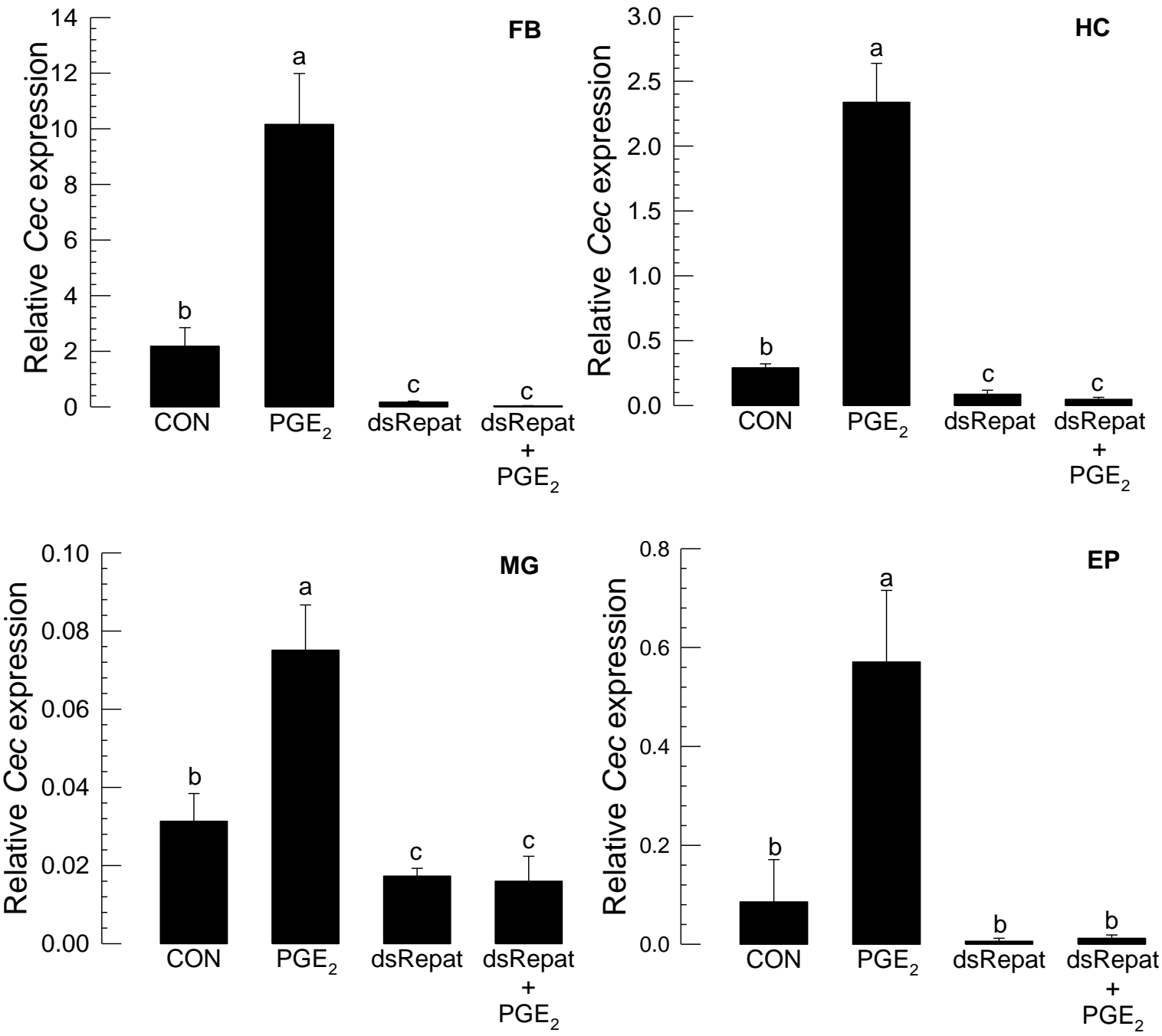

(b)

Figure 6. Cont. 


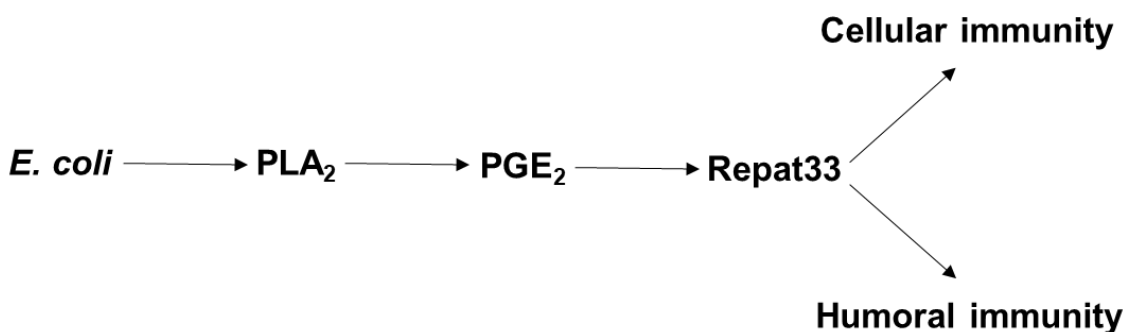

(c)

Figure 6. Repat33 as a downstream component of $\mathrm{PGE}_{2}$-mediating immune signal in S. exigua. (a) $\mathrm{PGE}_{2}-\mathrm{Repat}_{3}$ signaling in a cellular immune response assessed by hemocyte-spreading behavior. For the immune challenge, E. coli ( $10^{4}$ cells $/$ larva) was injected into L5 larvae. After $8 \mathrm{~h}$, hemolymph was collected and used for the hemocyte-spreading assay. PGE 2 was injected at a dose of $1 \mu \mathrm{g} /$ larva. RNA interference (RNAi) of Repat33 expression was performed by injecting dsRNA ('dsRepat', $1 \mu \mathrm{g} /$ larva) specific for Repat33. At $24 \mathrm{~h}$ after injection, larvae were treated with bacteria or PGE 2 . After $8 \mathrm{~h}$, hemolymph was collected and used for the hemocyte-spreading assay. For cytoskeleton analysis, F-actin filaments were specifically recognized by FITC-tagged phalloidin (green). The nucleus was stained with DAPI (blue). Each treatment was independently replicated three times. Scale bar represents $10 \mu \mathrm{m}$. (b) $\mathrm{PGE}_{2}$-Repat33 signaling in humoral immune response assessed by measuring cecropin ('Cec') expression levels at $8 \mathrm{~h}$ after bacterial challenge. A ribosomal protein gene, $R L 32$, was used as a reference gene for RT-qPCR. Each treatment was replicated three times with independent biological sample preparations. Different letters indicate significant differences among means at Type I error $=0.05$ (LSD test). (c) Immune signaling pathway involving $\mathrm{PGE}_{2}$ and Repat33.

\section{Discussion}

Repat family genes are known to be expressed in response to immune challenges in S. exigua. However, their physiological functions are little understood. This study investigated the role of Repat33, one of the Repat gene family members, in mediating cellular and humoral immune responses of S. exigua.

Repat33 was predicted to be a secretory protein due to its signal peptide. It also possessed a multiprotein-bridging factor 2 (MBF2) domain with 34-108 residues. MBF2 can activate transcription via its interaction with a transcriptional factor IIA (TFIIA) [33]. In Bombyx mori, it is known to form a complex with MBF1 and a DNA-binding regulator FTZ-F1 [34]. This suggests that Repat33 might act as a co-activator to link specific and general TFs to induce specific immune genes.

Repat33 was highly expressed in the last larval instar of S. exigua. It was expressed in all tested tissues such as the gut, epidermis, hemocytes, and fat body of the last larvae instar. Its expression was up-regulated after bacterial infection. However, the inducible expression of Repat33 after bacterial infection was suppressed by inhibition of eicosanoid biosynthesis. Injection of dexamethasone, a specific inhibitor of $\mathrm{PLA}_{2}$, significantly suppressed the expression of Repat33. However, the addition of arachidonic acid (AA), a catalytic product of PLA $\mathrm{P}_{2}$, significantly rescued such suppression of its gene expression. This suggests that Repat33 expression might be controlled by eicosanoids. This was further supported by RNAi treatment of PLA 2 expression which suppressed the inducible expression of Repat33 in response to bacterial challenge. The tested $\mathrm{PLA}_{2}$ was a secretory PLA $\left(\mathrm{Se}_{\mathrm{PLA}}\right)$ of $S$. exigua. Se-sPLA $\mathrm{A}_{2}$ can mediate AA release to produce various eicosanoids [15]. Eicosanoids are known to mediate both cellular and humoral immune responses in insects [4]. Especially, this current study showed that $\mathrm{PGE}_{2}$ could mediate the inducible expression of Repat33. Thus, AA addition to larvae treated with RNAi specific to Se-sPLA 2 expression significantly rescued the suppression of Repat33 expression. $\mathrm{PGE}_{2}$ is one of the well-known eicosanoids in S. exigua and other insects [35]. Recently, its receptor has been identified in Manduca sexta. It has been shown that $\mathrm{PGE}_{2}$ can bind to its specific receptor and increase the cAMP level in target cells [25]. A highly similar PGE 2 receptor (GenBank accession number: MN381016.1) was also found in S. exigua. cAMP can activate protein kinase A which then activates cAMP-responsive element-binding protein (CREB) [36]. CREB is then translocated into the 
nucleus to activate target genes. Based on this signal pathway, control of Repat33 expression by eicosanoids might be explained by the cAMP signal pathway in target cells. Indeed, the current study showed that $\mathrm{PGE}_{2}$ could induce the expression of Repat33. The hypothesis of $\mathrm{PGE}_{2}$-CREB-Repat33 needs to be explored in a subsequent study.

RNAi of Repat33 expression resulted in immunosuppression of S. exigua. Hemocytespreading behavior was significantly impaired by this RNAi treatment. Hemocyte-spreading behavior is required for most cellular immune responses of insects [5]. In S. exigua, the hemocyte behavior is mediated by eicosanoids, especially $\mathrm{PGE}_{2}$, by increasing actin cytoskeleton and stimulating aquaporin [35]. This suggests that Repat33 as a downstream factor of eicosanoids might play a crucial role in the cytoskeletal rearrangement of hemocytes. The impairment of hemocyte-spreading behavior induced by RNAi specific for Repat33 expression led to a significant decrease in nodule formation after bacterial challenge. Such RNAi treatment also suppressed the up-regulation of AMP gene expression in response to bacterial challenge. Eicosanoids can mediate AMP gene expression in Bombyx mori and Drosophila melanogaster [37,38]. Indeed, a functional cross-talk between Toll/IMD pathways and $\mathrm{PLA}_{2}$ activation in Tribolium castaneum has been reported [39]. Under PLA 2 inhibition, various eicosanoids can stimulate different immune-associated protein genes including AMPs in S. exigua [24]. These findings suggest that Repat33 can directly or indirectly activate AMP gene expression after an eicosanoid signal.

In summary, this study analyzed the expression and physiological functions of Repat33 in the immunity of S. exigua. Repat33 can mediate both cellular and humoral immune responses under the eicosanoid signaling pathway. Suppression of Repat33 expression can lead larvae to have an immunosuppressive state. This is the first study demonstrating that Repat family genes are involved in the regulation of immune responses.

Supplementary Materials: The following are available online at https:/ / www.mdpi.com/article/ 10.3390/insects12050449/s1, Table S1: List of primers used in this study.

Author Contributions: Conceptualization, Y.K.; methodology, M.T.H.H., S.A., and M.V.; software, M.T.H.H.; validation, M.T.H.H.; formal analysis, M.T.H.H.; investigation, M.T.H.H.; resources, Y.K.; data curation, M.T.H.H.; writing-original draft preparation, M.T.H.H.; writing-review and editing, Y.K.; visualization, M.T.H.H.; supervision, Y.K.; project administration, Y.K.; funding acquisition, Y.K. All authors have read and agreed to the published version of the manuscript.

Funding: This research was funded by the National Research Foundation (NRF) funded by the Ministry of Science, ICT and Future Planning, Republic of Korea, grant number 2017R1A2133009815.

Institutional Review Board Statement: Not applicable.

Data Availability Statement: Not applicable.

Conflicts of Interest: The authors declare no conflict of interest.

\section{References}

1. Lemaitre, B.; Hoffmann, J. The host defense of Drosophila melanogaster. Annu. Rev. Immunol. 2007, 25, 697-743. [CrossRef]

2. Strand, M.R.; Clark, K.D. Plasmatocyte spreading peptide induces spreading of plasmatocytes but represses spreading of granulocytes. Arch. Insect Biochem. Physiol. 1999, 42, 213-223. [CrossRef]

3. Janeway, C.A., Jr.; Medzhitov, R. Innate immune recognition. Annu. Rev. Immunol. 2002, 20, 197-216. [CrossRef]

4. Kim, Y.; Ahmed, S.; Stanley, D.; An, C. Eicosanoid-mediated immunity in insects. Dev. Comp. Immunol. 2018, 83, 130-143. [CrossRef]

5. Lavine, M.D.; Strand, M.R. Insect hemocytes and their role in immunity. Insect Biochem. Mol. Biol. 2002, 32, 1295-1309. [CrossRef]

6. Imler, J.L.; Bulet, P. Antimicrobial peptides in Drosophila: Structures, activities and gene regulation. Chem. Immunol. Allergy 2005, $86,1-21$.

7. Herrero, S.; Ansems, M.; Van Oers, M.M.; Vlak, J.M.; Bakker, P.L.; de Maagd, R.A. REPAT, a new family of proteins induced by bacterial toxins and baculovirus infection in Spodoptera exigua. Insect Biochem. Mol. Biol. 2007, 37, 1109-1118. [CrossRef] [PubMed]

8. Hernández-Martínez, P.; Navarro-Cerrillo, G.; Caccia, S.; de Maagd, R.A.; Moar, W.J.; Ferré, J.; Escriche, B.; Herrero, S. Constitutive activation of the midgut response to Bacillus thuringiensis in Bt-resistant Spodoptera exigua. PLoS ONE 2010, 5, e12795. [CrossRef]

9. Hernández-Rodríguez, C.S.; Ferré, J.; Herrero, S. Genomic structure and promoter analysis of pathogen-induced repat genes from Spodoptera exigua. Insect Mol. Biol. 2009, 18, 77-85. [CrossRef] [PubMed] 
10. Navarro-Cerrillo, G.; Ferré, J.; de Maagd, R.A.; Herrero, S. Functional interactions between members of the REPAT family of insect pathogen-induced proteins. Insect Mol. Biol. 2012, 21, 335-342. [CrossRef] [PubMed]

11. Stanley, D. Eicosanoids in Invertebrate Signal Transduction Systems; Princeton University Press: Princeton, NJ, USA, 2000.

12. Dennis, E.A. The growing phospholipase $\mathrm{A}_{2}$ superfamily of signal transduction enzymes. Trends Biochem. Sci. 1997, 22, 1-2. [CrossRef]

13. Park, Y.; Stanley, D.; Kim, Y. Eicosanoids up-regulate production of reactive oxygen species by NADPH-dependent oxidase in Spodoptera exigua phagocytic hemocytes. J. Insect Physiol. 2015, 79, 63-72. [CrossRef] [PubMed]

14. Sadekuzzaman, M.; Gautam, N.; Kim, Y. A novel calcium-independent phospholipase $\mathrm{A}_{2}$ and its physiological roles in development and immunity of a lepidopteran insect, Spodoptera exigua. Dev. Comp. Immunol. 2017, 77, 210-220. [CrossRef] [PubMed]

15. Vatanparast, M.; Ahmed, S.; Herrero, S.; Kim, Y. A non-venomous sPLA 2 of a lepidopteran insect: Its physiological functions in development and immunity. Dev. Comp. Immunol. 2018, 89, 83-92. [CrossRef]

16. Sajjadian, S.M.; Vatanparast, M.; Stanley, D.; Kim, Y. Secretion of secretory phospholipase $\mathrm{A}_{2}$ into Spodoptera exigua larval midgut lumen and its role in lipid digestion. Insect Mol. Biol. 2019, 28, 773-784. [CrossRef]

17. Stanley, D.; Kim, Y. Why most insects have very low proportions of C20 polyunsaturated fatty acids: The oxidative stress hypothesis. Arch. Insect Biochem. Physiol. 2020, 103, e21622. [CrossRef] [PubMed]

18. Hasan, M.A.; Ahmed, S.; Mollah, M.M.I.; Lee, D.; Kim, Y. Variation in pathogenicity of different strains of Xenorhabdus nematophila: Differential immunosuppressive activities and secondary metabolite production. J. Invertebr. Pathol. 2019, 166, 107221. [CrossRef]

19. Ahmed, S.; Stanley, D.; Kim, Y. An insect prostaglandin $\mathrm{E}_{2}$ synthase acts in immunity and reproduction. Front. Physiol. 2018, 9, 1231. [CrossRef]

20. Sajjadian, S.M.; Kim, Y. PGE 2 upregulates gene expression of dual oxidase in a lepidopteran insect midgut via cAMP signalling pathway. Open Biol. 2020, 10, 200197. [CrossRef]

21. Ahmed, S.; Al Baki, M.A.; Lee, J.; Seo, D.Y.; Lee, D.; Kim, Y. The first report of prostacyclin and its physiological roles in insects. Gen. Comp. Endocrinol. 2021, 301, 113659. [CrossRef]

22. Al Baki, M.A.; Roy, M.C.; Lee, D.; Stanley, D.; Kim, Y. The prostanoids, thromboxanes, mediate hemocytic immunity to bacterial infection in the lepidopteran Spodoptera exigua. Dev. Comp. Immunol. 2021, 120, 104069. [CrossRef] [PubMed]

23. Vatanparast, M.; Lee, D.H.; Kim, Y. Biosynthesis and immunity of epoxyeicosatrienoic acids in a lepidopteran insect, Spodoptera exigua. Dev. Comp. Immunol. 2020, 107, 103643. [CrossRef] [PubMed]

24. Shrestha, S.; Kim, Y. Various eicosanoids modulate the cellular and humoral immune responses of the beet armyworm, Spodoptera exigua. Biosci. Biotechnol. Biochem. 2009, 73, 2077-2084. [CrossRef] [PubMed]

25. Kwon, H.; Yang, Y.; Kumar, S.; Lee, D.W.; Bajracharya, P.; Calkins, T.L.; Kim, Y.; Pietrantonio, P.V. Characterization of the first insect prostaglandin $\left(\mathrm{PGE}_{2}\right)$ receptor: MansePGE2R is expressed in oenocytoids and lipoteichoic acid (LTA) increases transcript expression. Insect Biochem. Mol. Biol. 2020, 117, 103290. [CrossRef] [PubMed]

26. Kim, Y.; Ahmed, S.; Al Baki, M.A.; Kumar, S.; Kim, K.; Park, Y.; Stanley, D. Deletion mutant of PGE 2 receptor using CRISPR-Cas9 exhibits larval immunosuppression and adult infertility in a lepidopteran insect, Spodoptera exigua. Dev. Comp. Immunol. 2020, 111, 103743. [CrossRef]

27. Goh, H.G.; Lee, S.G.; Lee, B.P.; Choi, K.M.; Kim, J.H. Simple mass-rearing of beet armyworm, Spodoptera exigua (Hübner) (Lepidoptera: Noctuidae), on an artificial diet. Korean J. Appl. Entomol. 1990, 29, 180-183.

28. Kim, H.; Keum, S.; Hasan, A.; Kim, H.; Jung, Y.; Lee, D.; Kim, Y. Identification of an entomopathogenic bacterium, Xenorhabdus ehlersii KSY, from Steinernema longicaudum GNUS101 and its immunosuppressive activity against insect host by inhibiting eicosanoid biosynthesis. J. Invertebr. Pathol. 2018, 159, 6-17. [CrossRef]

29. Jung, S.; Kim, Y. An entomopathogenic bacterium, Xenorhabdus nematophila K1, enhances baculovirus pathogenicity against Spodoptera exigua and Plutella xylostella. J. Asia Pac. Entomol. 2006, 9, 139-143. [CrossRef]

30. Park, J.; Kim, Y. Phospholipase $\mathrm{A}_{2}$ inhibitors in bacterial culture broth enhance pathogenicity of a fungus Nomuraea rileyi. J. Microbiol. 2012, 50, 644-651. [CrossRef]

31. Bustin, S.A.; Benes, V.; Garson, J.A.; Hellemans, J.; Huggett, J.; Kubista, M.; Mueller, R.; Nolan, T.; Pfaffl, M.W.; Shipley, G.L.; et al. The MIQE guidelines: Minimum information for publication of quantitative real-time PCR experiments. Clin. Chem. 2009, 55, 611-622. [CrossRef]

32. SAS Institute, Inc. SAS/STAT User's Guide; SAS Institute: Cary, NC, USA, 1989.

33. Li, F.Q.; Takemaru, K.; Goto, M.; Ueda, H.; Handa, H.; Hirose, S. Transcriptional activation through interaction of MBF2 with TFIIA. Genes Cells 1997, 2, 143-153. [CrossRef] [PubMed]

34. Liu, Q.X.; Ueda, H.; Hirose, S. MBF2 is a tissue- and stage-specific coactivator that Is regulated at the step of nuclear transport in the silkworm Bombyx mori. Dev. Biol. 2000, 225, 437-446. [CrossRef] [PubMed]

35. Ahmed, S.; Kim, Y. PGE 2 mediates cytoskeletal rearrangement of hemocytes via Cdc42, a small G protein, to activate actinremodeling factors in Spodoptera exigua (Lepidoptera: Noctuidae). Arch. Insect Biochem. Physiol. 2019, 102, e21607. [CrossRef]

36. Sajjadian, S.M.; Ahmed, S.; Al Baki, M.A.; Kim, Y. Prostaglandin $\mathrm{D}_{2}$ synthase and its functional association with immune and reproductive processes in a lepidopteran insect, Spodoptera exigua. Gen. Comp. Endocrinol. 2020, 287, 113352. [CrossRef] [PubMed]

37. Morishima, I.; Yamano, Y.; Inoue, K.; Matsuo, N. Eicosanoids mediate induction of immune genes in the fat body of the silkworm, Bombyx mori. FEBS Lett. 1997, 419, 83-86. [CrossRef] 
38. Yajima, M.; Tanaka, M.; Tanahashi, N.; Kikuchi, H.; Natori, S.; Oshima, Y.; Kurata, S. A newly established in vitro culture using transgenic Drosophila reveals functional coupling between the phospholipase $\mathrm{A}_{2}$-generated fatty acid cascade and lipopolysaccharide-dependent activation of the immune deficiency (imd) pathway in insect immunity. Biochem. J. 2003, 371, 205-210. [CrossRef] [PubMed]

39. Shrestha, S.; Kim, Y. Activation of immune-associated phospholipase $\mathrm{A}_{2}$ is functionally linked to Toll/Imd signal pathways in the red flour beetle, Tribolium castaneum. Dev. Comp. Immunol. 2010, 34, 530-537. [CrossRef] [PubMed] 